\title{
Os observatórios ibero-americanos de informação, comunicação e cultura: balanço de uma breve trajetória
}

\author{
Luís A. Albornoz ${ }^{1}$ \\ Universidade Carlos III de Madri \\ luisalfonso.albornoz@uczm.es \\ Micael Herschmann² \\ Universidade Federal do Rio de Janeiro \\ micaelmh@globo.com
}

\begin{abstract}
Resumo: Este artigo analisa o recente fenômeno do crescimento do número de Observatórios de Informação, Comunicação e Cultura no contexto iberoamericano. Apresentam-se neste trabalho alguns dos resultados preliminares de uma investigação que tem como objetivo analisar o perfil e a atuação dos observatórios em atividade hoje.
\end{abstract}

Palavras chave: Comunicação; Cultura; Observatórios; Iberoamérica; Políticas Públicas.

Abstract: This article analyzes the recent phenomena of increased of the number of observatories that works in the fields of information, communication and culture in the Iberoamérica context. This paper presents the preliminary results of a research that have like goal classified and analyze the actuation of the observatories in activity today

Keyword: Communication; Culture; Observatory; Iberoamérica; Public Policies.

1 Doutor em Comunicação e secretário do grupo de pesquisa "Televisão: memória, representação e indústria" do Departamento de Jornalismo e Comunicação Audiovisual da Universidade Carlos III de Madri.

2 Doutor em Comunicação, Coordenador do Núcleo de Estudos e Projetos em Comunicação da ECO/UFRJ, Pesquisador do CNPq e Vice-Coordenador do Programa de Pós-Graduação em Comunicação e Cultura da Escola de Comunicação da Universidade Federal do Rio de Janeiro. 


\section{Introdução}

Nos últimos anos, o termo "observatório" encontra-se cada vez mais na ordem do dia, sendo abordado em seus discursos por políticos, jornalistas e pesquisadores sociais da Europa e da América Latina. Administrações públicas locais, regionais e nacionais, organizações de caráter supranacional - como a União Européia e o Mercosul - sindicatos, instituições acadêmicas e fundações vêm criando observatórios de diversos tipos com o objetivo de monitorar de forma sistemática o funcionamento de um setor ou temáticas específicas. Aliás, atualmente existem observatórios relacionados às mais variadas temáticas, tais como: o racismo e a xenofobia, a imigração, as relações industriais, a tecnologia, o meio ambiente e a violência de gênero. Até mesmo as autoridades do Museu do Louvre colocaram em funcionamento o seu próprio observatório com o objetivo de conhecer melhor o público que visita a prestigiosa pinacoteca parisiense.

É possível afirmar que os atuais observatórios tiveram sua origem na época da organização dos primeiros observatórios astronômicos modernos (durante os séculos XVIII e XIX em Greenwich, Paris, Cape Town e Washington D.C.). Ao mesmo tempo, contribuiu para o seu desenvolvimento a institucionalização e o largo uso dos serviços de estatística, por parte dos órgãos e entidades governamentais e administrativos, dentro do âmbito nacional e internacional.

Ainda que possamos definir os observatórios de diferentes maneiras, especialmente os observatórios sociais, está se considerando aqui como "organismos auxiliares, colegiados e integrados de forma plural, que têm a função de facilitar o acesso público à informação de qualidade e propiciar a tomada de decisões por parte das autoridades responsáveis" (Maiorano, 2003). Em geral, a função desses observatórios estaria associada as seguintes atividades: a) recopilação e elaboração de bases de dados; b) metodologias para codificar, classificar e categorizar informações; c) conexão entre pessoas e organizações que trabalham em áreas similares; d) aplicações específicas de novas ferramentas técnicas; e) análise de tendências/publicações (PNUD-Panamá, 2004). 
Entre os diversos observatórios sociais identificados na pesquisa - sejam eles locais, regionais ou nacionais - constatou-se que a maioria foi criada na segunda metade da década de 1990 e que, com alguma freqüência, conformariam redes enquanto uma estratégia de trabalho capaz de potencializar sua forma de atuar. Poder-se-ia oferecer dois exemplos de redes de âmbito internacional, criadas pela Organização das Nações Unidas para a Educação, a Ciência e a Cultura (UNESCO): a Rede Internacional de Observatórios das Políticas Culturais ${ }^{3}$ que busca vincular e articular observatórios, institutos e centros de pesquisa de diversas partes do mundo; e o Sistema Regional de Informação (SIRI) cujo objetivo é o de contribuir para gerar, reunir e disseminar dados relativos à educação na América Latina, com o objetivo de melhorar os sistemas educativos e proporcionar um atendimento de qualidade a todos ${ }^{4}$.

\section{Desafios à investigação}

Ao realizar este estudo buscou-se conhecer melhor o perfil e a atuação dos Observatórios de Informação, Comunicação e Cultura no contexto ibero-americano ${ }^{5}$. A escolha deste objeto de estudo foi motivada pelo interesse em repensar a emergência de um novo tipo de organismo ou instituição direcionado à observação e análise do comportamento de setores, atividades e serviços relacionados à informação, comunicação e cultura. Tais organismos desempenham hoje uma função importante, pois monitoram empresas que desenvolvem um papel estratégico nos campos ideológico (transmissão de comportamentos/valores e construção de identidades sociais) e econômico (produção, emprego e consumo) no seio das sociedades capitalistas contemporâneas.

A fim de cumprir os objetivos propostos na investigação em curso, realizou-se um levantamento inicial tomando-se como parâmetro as seguintes indagações: Quantos observatórios estão operativos? Quais são as suas características básicas? Como são financiadas e configuradas as suas linhas de atuação? Que tipo de trabalhos realizam e

3 Para mais informações ver o site da Rede Internacional de Observatórios de Políticas Culturais, link: www.unesco.org/culture/development/observatories/html sp/index sp.shtml; último acesso: 22.04.2006. 4 Conferir informações do site do Sistema Regional de Informação (SIRI), link: http://siri.unesco.cl/quienes.act?f=F; último acesso: 22.04.2006.

5 Agradecemos a assistente de pesquisa Beatriz Buarque pelo o auxílio no levantamento do material. Um agradecimento especial também ao apoio concedido pelas agências de fomento à pesquisa: CAPES e CNPq para a realização desta investigação. 
como se relacionam com os diversos agentes públicos e privados? Qual é o nível de participação da sociedade civil no dia a dia dos observatórios? Que tipo de redes estão construindo ao longo da sua trajetória? Como estão constituídos juridicamente?

Cabe ressaltar que, no estágio inicial desta investigação, deparamo-nos com três grandes desafios. O primeiro inerente a qualquer fenômeno recente: a escassa reflexão teórica sobre estes novos organismos, principalmente nos países ibero-americanos. No entanto, a contribuição pioneira de alguns autores (como Ramonet, 2003; Rey, 2003; Getino, 2004; Alfaro Moreno, 2004; Mattelart, 2005; Bruollón Pastoriza e outros, 2005) ofereceu uma base mínima para a construção de uma análise sobre as características e funções dos observatórios. Na realidade, no espaço ibero-americano, o pouco debate e reflexão existente, foram especialmente incentivados: a) pelo II Fórum Social Mundial (Porto Alegre, 2002) durante o qual se promoveu o lançamento do Observatório Internacional de Meios de Comunicação; ${ }^{6}$ b) pela criação da Oficina de Trabalho "Observatórios e ouvidorias cidadãs dos meios de comunicação na América Latina" (Buenos Aires, 2003) ${ }^{7}$; c) e pelo II Encontro Internacional sobre Diversidade Cultural - As Indústrias Culturais na Globalização (Buenos Aires, 2004), que contou com uma mesaredonda reunindo especialistas, intitulada "Observatórios de políticas culturais: experiências locais e regionais" $"$.

O segundo desafio identificado na investigação está relacionado à "diversidade" que caracteriza o universo desses observatórios. Em outras palavras, a grande variedade de origens, estruturas, temáticas tratadas, objetivos programáticos, metodologias utilizadas, âmbitos de atuação e grau de evolução, que caracterizam hoje o universo dos observatórios sociais, são em geral pouco perceptíveis ao público, mas afeta de forma significativa o

6 O Observatório Internacional de Medios de Comunicação, o Media Watch Global (www.mwglobal.org) foi criado no II Forum Mundial Social (realizado em Porto Alegre entre 31 de janeiro e 5 de fevereiro de 2002) e institucionalizado em Paris um ano depois. Atualmente está presidido por Ignacio Ramonet e conta com o apoio da publicação Le Monde Diplomatique e da agência informativa Inter Press Service (IPS). A associação internacional MWG promove a criação de capítulos nacionais. França, Brasil, Itália e Venezuela já contam com observatórios associados e integrados à MWG.

7 Esta Oficina foi organizada pelo Projeto latino-americano de Meios de Comunicação da Fundação Friedrich Ebert (FES) e pelo Espaço La Tribu - Meios, Comunicação e Cultura. Foi realizada em Buenos Aires, entre os dias 4 e 6 de agosto de 2003.

8 Este Encontro, realizado entre os dias 9 e 11 de setembro de 2004, foi organizado pela Secretaria da Cultura da Cidade de Buenos Aires. 
trabalho desses organismos. Assim, encontramos em funcionamento na nossa investigação - na Espanha, Brasil e Argentina, países em que mais vêm sendo criados esses organismos nos últimos anos - inúmeros observatórios dedicados às tecnologias da informação e comunicação, ao jornalismo e às políticas e indústrias culturais com perfis e trajetórias bastante variadas

E, finalmente, o outro desafio encontrado refere-se aos dados públicos disponibilizados pelos próprios observatórios. Cabe ressaltar que há vários observatórios que proporcionam informações incipientes sobre a sua forma de atuar: com alguma freqüência encontramos observatórios que não possuem instrumentos eficientes de divulgação (vários não estão presentes na Internet ou possuem sites que não são atualizados com alguma regularidade).

Assim, neste artigo buscou-se oferecer - àqueles que querem pesquisar ou compreender o fenômeno dos observatórios sociais presentes no espaço ibero-americano não só um breve mapeamento, mas também uma tipologia dos que estão em funcionamento hoje.

\section{Criação e perfil dos Observatórios}

Embora haja uma grande variedade e riqueza de observatórios de informação, comunicação e cultura é possível dividi-los em dois conjuntos, com os seguintes enfoques básicos: um primeiro grupo, em que os observatórios são concebidos como espaços articuladores da cidadania a partir do qual pode-se monitorar o funcionamento dos meios de comunicação ("observatório fiscal”) e, outro, em que são considerados como novos organismos que colaboram através de suas intervenções e relfexões na formulação de políticas públicas ("observatório think tank").

A primeira concepção de observatório - fiscal - nos últimos anos foi promovida dentro e fora da comunidade científica por Armand Mattelart e Ignacio Ramonet, fundadores do Observatório Global de Meios de Comunicação. Em um artigo de ampla repercussão, intitulado "Fiscalização cidadã dos meios de comunicação", Ramonet (2003) propõe considerar os observatórios uma espécie de "quinto poder", um novo núcleo de poder, cujo protagonista seria a sociedade civil, orientado a "denunciar o grande poder dos 
grandes grupos mediáticos, cúmplices e difusores da globalização liberal”. Para o diretor do Le Monde Diplomatique, o papel do Media Global Watch seria o de denunciar e repreender “(...) as faltas de honestidade mediáticas através de relatórios e estudos que elabora, publica e difunde".

Neste sentido, este tipo de observatório - como as ouvidorias dos meios de comunicação - estaria fortemente vinculado aos conceitos de cidadania e democracia participativa, apresentando-se, ao mesmo tempo, como uma instância que ultrapassa as figuras do ombudsman e do defensor do leitor ou os códigos deontológicos das empresas jornalísticas. Em outras palavras, este tipo de organismo se constituiria fundamentalmente em um espaço de confluência de três tipos de atores: jornalistas, pesquisadores e usuários dos meios de comunicação.

A segunda concepção de observatório é a do think tank ${ }^{9}$, o qual é considerado aqui como um organismo com capacidade de intervir na elaboração das políticas públicas direcionadas a questões que dizem respeito aos setores da informação, da comunicação e/ou da cultura. Assim, para o coordenador do Observatório de Indústrias Culturais da Cidade de Buenos Aires, Octavio Getino (2004), o desafio deste trabalho de observação e análise não é tanto o de denunciar ou criticar (o que é também uma possibilidade legítima), mas o de orientar com o fim de elaborar idéias e propostas que contribuam para o aperfeiçoamento das políticas de algum setor e/ou que promovam o desenvolvimento do conjunto das indústrias culturais locais/nacionais, sempre tendo como parâmetro os interesses coletivos e não somente os interesses de um setor específico.

Este tipo de observatório pretende articular as suas pesquisas e intervenções com a elaboração de políticas públicas, através da construção de diagnósticos, avaliando o comportamento de um ou mais setores e/ou planejamento de projetos. Para a implementação dessas atividades, os coordenadores desses organismos dispõe de indicadores e ferramentas metodológicas, de caráter quantitativo e qualitativo. Em geral, este tipo de observatório está inserido na própria estrutura do aparato estatal e, portanto, é

9 O conceito anglo-saxão think tank começou a ser utilizado nos anos de 1950 para designar as organizações que aglutinam pesquisadores de diferentes campos do conhecimento, dedicadas a proporcionar advertências e idéias sobre um amplo número de problemáticas relacionadas com a implementação de políticas públicas (mais informações, ver: http://en.wikipedia.org/wiki/Think tank). 
financiado com recursos públicos. Vários responsáveis e coordenadores de tais organismos os consideram como uma espécie de "mesa de diálogo e concertação" sustentados por diversos agentes sociais, sejam eles do setor acadêmico, do produtivo/cultural ou dos órgãos estatais (Getino, 2004).

Analisando estes dois tipos de observatórios é possível, de um modo geral, constatar o caráter progressista e inovador dos mesmos. A meta de ambos é a transformação dos observatórios, na sua articulação com a sociedade civil, em agentes dinamizadores da democratização dos campos da informação, da comunicação e da cultura.

\section{Adversidades do contexto ibero-americano}

De modo geral, os agentes sociais identificam uma série de adversidades que vêm sendo enfrentadas nos países ibero-americanos e que, em alguma medida, motivou que a sociedade se organizasse e criasse observatórios nesta macrorregião:

- Altos indices de concentração da propriedade dos meios de comunicação. Grandes grupos como Prisa (Espanha), Globo (Brasil), Televisa (México), Clarín (Argentina) e Cisneros (Venezuela) são exemplos eloqüentes de empresas multimídia que se encontram em uma posição hegemônica nos seus respectivos mercados nacionais e que, em alguns casos, estão começando a se expandir internacionalmente. Emissoras de rádio e televisão, produtoras audiovisuais, publicações periódicas de informação geral, editoras e serviços de Internet são alguns dos diversos tipos de atividades econômicas dos conglomerados empresariais desta natureza e que têm uma clara influência político-ideológica.

- Relação simbiótica entre os meios de comunicação e poder político. Infelizmente, a posse e a utilização da mídia pelos principais grupos políticos é um fenômeno muito comum nos países ibero-americanos. O caso do Brasil pode ajudar a ilustrar a simbiose entre política e meios de comunicação que ocorre em alguns países. Em março de 2006 uma investigação feita pelo Instituto para o Desenvolvimento do Jornalismo (PROJOR), que coordena o Observatório da Imprensa, revelou que um de cada dez deputados federais é dono de um veículo de comunicação (em geral emissoras de rádio e televisão). Segundo Venício Lima, 
coordenador desta pesquisa, esta situação contradiz a própria Carta Magna brasileira e cria um conflito entre os interesses privados e o bem comum ${ }^{10}$.

- Crítica aos conteúdos oferecidos pelos sistemas mediáticos. Diversas organizações sociais (associações profissionais e de usuários, sindicatos e fundações, entre outros), intelectuais e jornalistas dos países ibero-americanos vêm denunciando a pouca pluralidade e, inclusive, a baixa "qualidade" dos conteúdos difundidos pelos diferentes meios de comunicação. A maioria das denúncias está dirigida especialmente ao veículo de comunicação hegemônico hoje: a televisão. No entanto, este tipo de reclamação atinge todo o conjunto dos sistemas mediático-comerciais, cujo principal objetivo é a mobilização da audiência. A situação é especialmente delicada no campo informativo, no qual, com grande freqüência, podem-se constatar formas de censura e de auto-censura, conduzindo a invisibilidade de problemáticas e vozes e descontextualização de informação. Mediante uma informação cada vez mais contaminada pelos interesses particulares, alguns críticos defendem a necessidade de promover uma "ecologia da informação" (Mattelart, 2005).

- Obscurantismo dos dados referentes aos setores de informação, comunicação e cultura. A grande maioria dos países ibero-americanos carece de estatísticas sistemáticas e confiáveis elaboradas por organismos independentes. A situação do setor do jornalismo impresso na América Latina, segundo inúmeros atores sociais, necessita de mais atenção de entidades do Estado e da sociedade civil. No final da década passada, Díaz Nosty (1999) constatou a inexistência de organismos imparciais na hora de certificar a difusão da imprensa escrita em El Salvador, Guatemala, Honduras, Nicarágua, Chile, Venezuela, Colômbia, Equador, Peru, Bolívia e México. Inclusive, mesmo em países onde há organismos verificadores de circulação, a confiabilidade das cifras do setor é questionada com freqüência.

- Desconhecimento das relações entre cultura e economia - constatável pela falta de indicadores qualitativos e quantitativos das atividades culturais - que permitiriam a comparação entre setores, países e blocos regionais. As Administrações públicas dos países ibero-americanos não consideram as atividades culturais como um setor econômico

10 Mais informações ver site do Observatório de Imprensa (http://observatorio.ultimosegundo.ig.com.br). 
diferenciado dentro dos seus respectivos Sistemas de Contas Nacionais ${ }^{11}$. Assim, os Estados continuam desconhecendo o verdadeiro peso econômico do conjunto de atividades culturais no Produto Interno Bruto (PIB), pois os dados permanecem ocultos, ou melhor, diluídos nas contas de diversos setores, ramificações e atividades da economia de um país. Consciente destas carências o trabalho desenvolvido no Projeto "Economia e Cultura" do Convênio Andrés Bello (CAB) vem dando uma importante contribuição ao fomentar a realização pesquisas sobre o impacto econômico das indústrias culturais no Peru, Chile, Colômbia, Equador e Venezuela.

\section{Resultados preliminares da investigação}

De forma muito sintética apresenta-se a seguir uma descrição da investigação que está sendo realizada e que está basicamente dividida em duas etapas:

Na primeira etapa - executada entre janeiro e abril de 2006 - foram realizadas as seguintes atividades de pesquisa: a) levantamento e análise de material bibliográfico e hemerográfico relacionado com o tema dos observatórios de informação, comunicação e cultura; b) levantamento dos observatórios operativos, visando à análise e a elaboração de uma base de dados e classificação dos mesmos. Nesta etapa também foi selecionado um conjunto de observatórios, do âmbito europeu e internacional, que no futuro poderão servir de parâmetro para a presente pesquisa, centrada no contexto ibero-americano.

Com o objetivo de aprofundar as informações iniciais sobre os observatórios está prevista uma segunda etapa que será realizada durante o segundo semestre de 2006, durante a qual será preparado um questionário (em espanhol e português), a partir do qual serão elaboradas avaliações quantitativas e qualitativas do trabalho, da estrutura, e do modus operandi dos observatórios em atividade.

A seguir apresentam-se os principais dados quantitativos obtidos no levantamento realizado durant

I) Localização geográfica: detectou-se a presença de 55 observatórios de diferentes tipos, estabelecidos nas principais cidades de onze países ibero-americanos. A Espanha é o

\footnotetext{
11 Para uma compreensão da importância do Sistema de Contas Nacionais (SCN) e Conta Satélite, ver o texto apresentado por Paula Pobrete Maureira, no II Encontro Internacional sobre Diversidade Cultural As indústrias culturais na globalização, Buenos Aires, setembro de 2004.
} 
país que conta com mais observatórios, com 24 no total; seguido do Brasil com sete, e da Argentina, Colômbia e Uruguai, com quatro cada um.

Quadro $\mathrm{n}^{\circ}$ 1: Localização dos observatórios por país (em porcentagem)

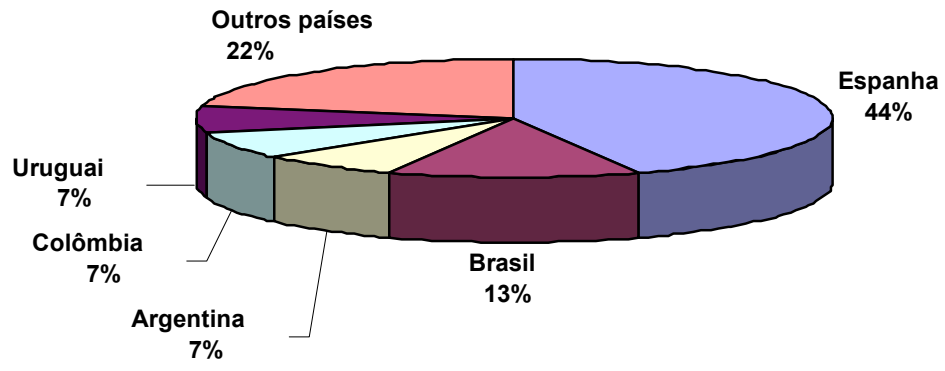

Fonte: elaboração própria.

II) Temáticas: com respeito às temáticas abordadas pelo conjunto dos observatórios, os resultados revelam que há três tópicos dominantes: a) há os observatórios dedicados a avaliar as tendências das indústrias culturais e a colaborar na formulação de políticas culturais (20 ao todo ou 36 por cento); b) existem também os observatórios dedicados a auscultar o desenvolvimento da Sociedade da Informação - em escala local, regional e nacional - e acompanhar à implantação de novas tecnologias de informação e comunicação (18 ao todo ou 33 por cento); e c) e há, ainda, os observatórios dedicados a fiscalizar os conteúdos veiculados pelos meios de comunicação (17 ao todo ou 31 por cento). 
Quadro no 2: Observatórios classificados por temática (em porcentagem)

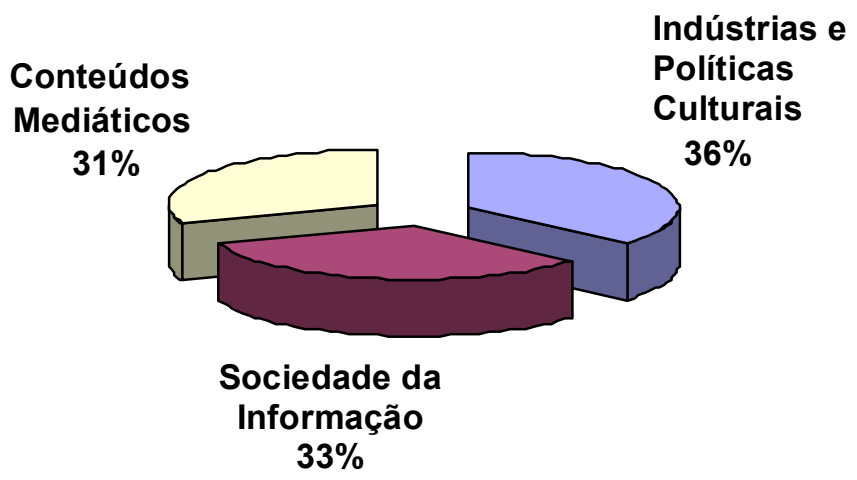

Fonte: elaboração própria.

Os três tópicos principais abordados pelos observatórios ibero-americanos englobam as seguintes temáticas:

- Indústrias e políticas culturais: dos 20 observatórios dedicados a este tema, a grande maioria (18) dedica-se a monitorar o conjunto dos setores culturais e fazer uma balanço e acompanhamento das políticas culturais. Os outros dois estão relacionados mais diretamente com o setor audiovisual. Cabe ressaltar que a grande maioria deles está financiada com dinheiro público.

- Sociedade da Informação: dos 18 observatórios que trabalham com esta temática destacam-se os observatórios dedicados a monitorar a implantação das Tecnologias de Informação e Comunicação (TICs) no âmbito nacional (quatro) e regional (dez) na Espanha. Há também dois observatórios internacionais pertencentes à UNESCO (um com sede em Montevidéu, para os países de língua espanhola, e outro em Lisboa, para os países de língua portuguesa). Com respeito aos dois restantes, um trabalha com questões relacionadas com a democracia digital, e o outro, com aspectos da cibersociedade.

- Conteúdos Mediáticos: identificamos 17 observatórios que trabalham com temáticas relacionadas principalmente com a oferta de informação disponibilizada pelos meios de comunicação. Isto inclui não só os capítulos venezuelano e brasileiro do Observatório Global de Meios (MWG), mas também os observatórios relacionados: às 
problemáticas do ciberjornalismo (cinco), a questões que dizem respeito à promoção e ampliação da cidadania (cinco), e tópicos relativos a questões ético-profissionais (três), de saúde (um) e de educação (um).

III) Âmbito de atuação: ao avaliar as áreas de atuação dos observatórios pesquisados - local/regional, nacional e internacional - constatou-se: que quase a metade deles (26 de um universo de 55) atua em um âmbito nacional, mais de um terço (21) vem desenvolvendo seus trabalhos no âmbito local (regional) e o resto (oito) centra o seu campo de análise em dois ou mais países. Também se pode atestar que a maioria deles carece de uma articulação internacional mais efetiva através da dinamização de redes envolvendo estes organismos.

Quadro no 3: Observatórios por âmbito de ação (em porcentagem)

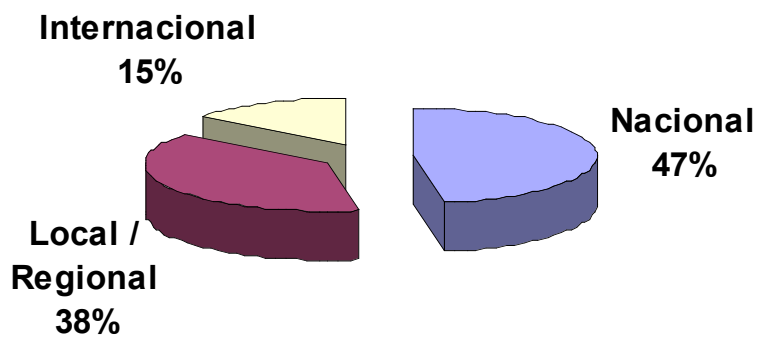

Fonte: elaboração própria.

IV) Fontes de financiamento: ao examinar a proveniência dos recursos dos observatórios pesquisados identificamos uma preponderância de fundos públicos. Quase dois terços dos observatórios são financiados com recursos públicos e um terço recebe dinheiro de organizações da sociedade civil. Os observatórios com financiamento misto representam uma porcentagem marginal. 
Quadro n ${ }^{\circ}$ 4: Fontes de financiamento dos Observatórios (em porcentagem)

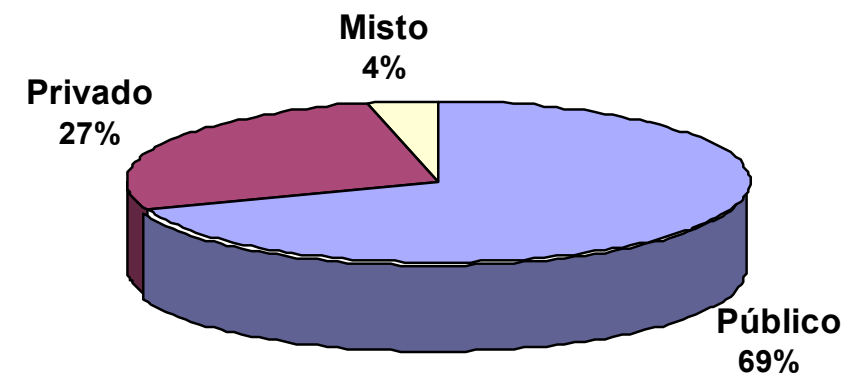

Fonte: elaboração própria.

Ao analisarmos o financiamento dos observatórios de Indústrias Culturais e de Políticas Culturais nos deparamos com a seguinte situação: a grande maioria deles (18 de 20) está financiada com dinheiro público e, inclusive, alguns operam dentro de entidades públicas. Nota-se também que o número de observatórios (dois) financiados com dinheiro do setor privado é pouco representativo.

Quadro $n^{\circ}$ 5: Financiamento dos Observatórios de Indústrias e Políticas Culturais (em porcentagem)

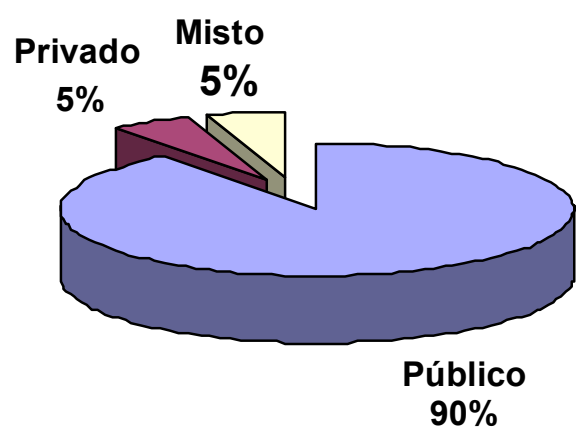

Fonte: elaboração própria.

$\mathrm{Na}$ análise das fontes de financiamento dos observatórios relacionados com a Sociedade da Informação e as TICs, verificamos que a grande maioria também opera com 
recursos públicos (15), sendo pouco significativo o financiamento privado neste tipo de observatórios (três).

Quadro $n^{\circ}$ 6: Financiamento dos Observatórios da Sociedade da Informação (em porcentagem)

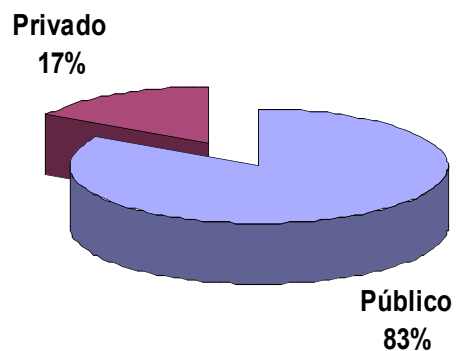

Fonte: elaboração própria.

No que se refere aos observatórios que fiscalizam os conteúdos emitidos pelos meios de comunicação, o financiamento é majoritariamente privado (11) dado que um número significativo deles é fruto de iniciativas da sociedade civil.

Quadro no 7: Financiamento dos Observatórios fiscalizadores de Conteúdos Mediáticos (em porcentagem)

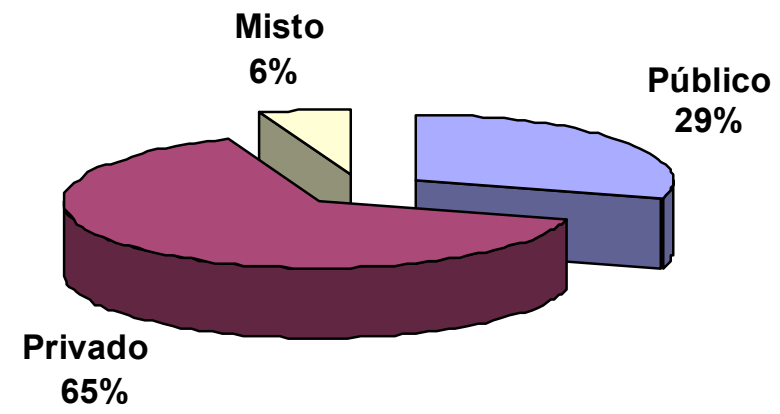

Fonte: elaboração própria. 


\section{Considerações finais}

A proliferação de observatórios de informação, comunicação e cultura é um fenômeno de múltiplas dimensões que atinge ao conjunto das sociedades que conformam o mosaico ibero-americano. Nesta proliferação convergem esforços, tanto por parte das administrações públicas - locais, regionais e nacionais - como da sociedade civil.

De modo geral, a primeira fase da pesquisa indica que os observatórios nos países ibero-americanos estão orientados a concretização das seguintes metas:

A implementação de políticas públicas e comportamento dos agentes sociais de um determinado setor ou de um conjunto de setores das indústrias culturais;

A elaboração, implantação e acompanhamento de projetos relacionados com o desenvolvimento da Sociedade da Informação;

Avaliação dos conteúdos de entretenimento, informação e educação veiculados pelos meios de comunicação mais massivos.

A esta altura poder-se-ia perguntar: Realizar uma análise centrada nos observatórios pode efetivamente ajudar a conhecer o que está acontecendo nos âmbitos da informação, da comunicação e da cultura? Quais são as implicações que acarreta o surgimento destes organismos para a democracia? O trabalho dos observatórios contribui para o debate público? Estes novos agentes têm realmente a capacidade de influenciar aqueles que controlam a produção informativa e cultural? Se considerarmos o estado inicial no qual se encontra a pesquisa, estas e outras perguntas ainda não podem ser respondidas plenamente, contudo é possível fazer algumas considerações, prévias e apresentar um resumo das mesmas na seguinte matriz $\mathrm{DAFO}^{12}$ :

12 Para mais informações das aplicações deste tipo de matriz, conferir Bustamante, 2002: 15-17. 
- Forte presença hoje do termo "observatório".

- Diversidade de objetivos e metodologias

empregadas.

- Canais de difusão pouco consolidados.

- Organismos jovens: falta de experiência e

conhecimento da capacidade plena de atuação dos

observatórios.

- Escassa vinculação entre os observatórios.
- Adoção de uma postura tecnocrata e/ou autoritária.

- Constituir-se em parte da engrenagem da burocracia estatal/setorial.

- Ausência de coordenação/indistinção com outros organismos.

- Constituir-se em instância de lobby dos poderes políticos e econômicos.

- Falta de diálogo com os cidadãos.

\section{Fortalezas (virtudes)}

\section{Oportunidades}

- Entorno propício: consciência da importância - Contribuir na democratização da comunicação, das atividades culturais. da informação e da cultura.

- Sistematização de dados e informações

- Disponibilidade de TICs.

- Intervir na geração de políticas públicas e setoriais.

- Descobertas de tendências e projeção de cenários.

- Consolidar mecanismos de participação cidadã. - Constituir-se em um ator independente dos

- Organismos jovens: cultura da organização em poderes políticos e econômicos. construção.

- Formar pessoal especializado de maneira sistemática.

Fonte: elaboração própria.

- Em primeiro lugar, é possível atestar que nos últimos anos autoridades governamentais, acadêmicos e cidadãos dos países ibero-americanos têm tomado consciência do peso que o conjunto das atividades culturais tem nas economias locais/nacionais e da estreita relação entre essas atividades e o desenvolvimento endógeno. Sem dúvida, sobre este fato têm contribuído os debates internacionais em torno à “exceção” e à "diversidade cultural” (Albornoz, 2006) e a crescente preocupação nos países ocidentais com a concentração e influência dos meios de comunicação. No meio acadêmico esta tomada de consciência é perceptível se analisamos o maior interesse por parte dos pesquisadores sociais em compreender as relações entre cultura, economia e 
processos sociais e que se manifesta, por exemplo, na realização de atividades de formação pós-graduada nos campos da economia da cultura e da gestão cultural. No meio políticogovernamental, uma das reações das administrações tem sido a de incorporar a pesquisa sistemática no momento de avaliar o funcionamento das Políticas Públicas e a situação das Indústrias Culturais. Além disso, as administrações estão atentas aos recursos (obtidos através de exportações, turismo, impostos, consumo, etc.) que as diversas atividades culturais podem gerar. Na realidade, é possível atestar que em seus discursos, as autoridades vêm enfatizando a necessidade de regular e monitorar a atuação das indústrias culturais. A existência de vinte observatórios de Indústrias e Políticas Culturais financiados com recursos públicos parece confirmar tal preocupação.

- Em segundo, a irrupção de tecnologias digitais inovadoras nos últimos anos abriu espaço para a elaboração de projetos destinados a conformar a denominada Sociedade da Informação (SI). Fomentar o desenvolvimento de infra-estruturas tecnológicas e o uso das TICs com a finalidade de evitar a ampliação de um quadro de exclusão social é um tópico bastante presente na agenda dos governos ibero-americanos. Até o momento, a Espanha através da administração central e de suas províncias -, é o único país que optou em criar observatórios para monitorar a implantação da SI. Esta é uma estratégia incentivada pela própria UNESCO. Aliás, esta entidade também tomou a iniciativa de criar dois observatórios da SI para os países ibero-americanos: um para os países de língua portuguesa, localizada no Brasil e, outro, para os países de língua espanhola, no Uruguai.

- E, finalmente, vale a pena destacar ainda o panorama complexo em que estão inseridos os meios de comunicação. As ditaduras sofridas no século passado pelos países ibero-americanos, unidas à exploração instrumental do conjunto do sistema de meios de comunicação pelos poderes políticos são elementos que não propiciam um ambiente favorável a qualquer tipo de intervenção pública no que se refere aos Conteúdos Mediáticos. Além disso, os processos de concentração e transnacionalização empresarial das indústrias culturais que ocorreram nos últimos cinco anos na região contaram com o beneplácito dos governos no poder, provocando críticas por parte de diferentes setores sociais. O corolário desta situação é que no contexto atual identificamos, por um lado, a desconfiança dos cidadãos com respeito às administrações públicas e, por outro, a reação constante por parte 
do setor privado-comercial que considera qualquer possível intervenção do Estado como um ato de censura incompatível com o princípio de liberdade de expressão em uma democracia.

Diante desta situação, os observatórios dedicados a fiscalizar o próprio sistema mediático e os seus conteúdos só poderiam ter sido concebidos a partir de iniciativas promovidas pela sociedade civil $^{13}$. Assim, a grande maioria dos observatórios criados para fiscalizar questões relacionadas com o fluxo de conteúdos veiculados pelos media é o resultado do trabalho de fundações, associações profissionais, sindicatos e, de modo geral, de ONGs. No entanto, as organizações da sociedade civil nos países ibero-americanos representam um amplo leque cultural e político que abrange desde grupos conservadores preocupados com a "qualidade" dos conteúdos televisivos e seu impacto no plano educativo sobre crianças e adolescentes, até organizações seculares, de caráter "progressista", orientadas a denunciar a influência das complexas relações entre governos e poder econômico que interferem nos fluxos informativos.

Utilizando a tipologia proposta ao longo deste artigo, poder-se-ia afirmar que tanto os observatórios do tipo think tank (mais dedicados a analisar as indústrias/ políticas culturais e o desenvolvimento da Sociedade da Informação), quanto os observatórios de tipo fiscal (orientados a avaliar a atuação dos meios de comunicação de massa e os seus conteúdos mediáticos) são fundamentais para construir um cenário mais equilibrado no contexto ibero-americano.

Como foi possível constatar ao longo deste texto, a criação de observatórios na região responde a uma diversidade de interesses e de questões que estão em jogo. Somente uma ação sustentável no tempo será capaz de revelar se no futuro poderão vir a se constituir em importantes agentes dinamizadores da necessária democratização das estruturas de informação, comunicação e cultura nesta macrorregião.

\footnotetext{
13 A sociedade civil engloba uma diversidade de espaços, agentes e formas institucionais, variando o seu grau de formalismo e autonomia. Entre os coletivos que conformam a rede da sociedade civil existem ONGs, associações e grupos comunitários, organizações de mulheres, organizações religiosas e associações profissionais. (conferir Site Centre for Civil Society, London School of Economics; link: www.lse.ac.uk/collections/CCS/introduction.htm, último acesso: 15.04.06).
} 


\section{Referências Bibliográficas:}

ALBORNOZ, Luís A. (2006). "Políticas públicas e industrias culturales: El desafío de la diversidad en Iberoamérica" in: Anuario del ININCO. Caracas: Instituto de Investigaciones de la Comunicación da Facultad de Humanidades y Educación de la Universidad Central de Venezuela, vol. 17, número 2.

ALFARO MORENO, Rosa Maria (2004). "Ardua democratización. Las batallas de un observatorio de medios” in: Etcetér@. Cidade do México (in: www.etcetera.com.mx/pag57ne48.asp, último acesso:23.03.2006).

BELTRÁN, Luís Ramiro (2005). “Observatorio de meios: cel quinto poder?” in: $L a$ Prensa. El Salvador: 17.06.2005 (in: http://166.114.28.115/20050617/opinion/opiniono4.htm, último acesso: 5.01.2006).

BROULLÓN PASTORIZA, Gaspar e outros (2005). "Los observatorios de comunicación"in: Chasqui. Quito: n. 90, pp. 38-45.

BUSTAMANTE, Enrique. (coord.) (2002). Comunicación y cultura en la era digital. Barcelona: Ed. Gedisa.

Consejo Nacional de la Cultura y las Artes de Chile (2003). Impacto de la cultura en la economía chilena: participación de algunas actividades culturales en el PIB y evaluación de las fuentes estadísticas disponibles. Bogotá: Convênio Andrés Bello (in:

www.cab.int.co/cab42/downloads/libro impacto cultura economia chilena .pdf. último acesso:15.01.2006).

HERRERA DAMAS, Susana (2005). "Retrato en diez rasgos de los observatorios de medios en América Latina” in: Sala de Prensa. Peru: n. 84, vol. VII, Año 3 (in: www.saladeprensa.org/art638.htm, último acesso: 28.03.2006).

DÍAZ NOSTY, Bernardo (1999). "La difusión de la prensa en lengua española" in: $E l$ español en el mundo. Anuario 1999. Madrid: Instituto Cervantes.

GETINO, Octavio (2004). Ponencia presentada en la sección "Observatorios de Políticas Culturales: experiencias locales y regionales" in: II Encuentro Internacional sobre Diversidad Cultural. Buenos Aires (in: www.buenosaires.gov.ar/areas/cultura/observatório/index.php?menu id=69 33, último acesso: 28.03.2006).

JARQUÍN, Aura (2006). "Observatorio de medios: un contrapoder de la sociedad civil” in: El Periódico y Editorial Nuevo Enfoque. El Salvador, 02.03.2006 (in: www.libros.com.sv/edicion54/index.html, último acesso: 28.03.2006).

MAIORANO, Jorge Luis (2003). "Los observatorios de derechos humanos como instrumento de fortalecimiento de la sociedad civil” in: Revista Probidad, El Salvador: n. 24.

MATTELART, Armand (2004). "Experto belga pide observatorio de los medios", en I Foro de las Américas. Quito, 30.07.04 (in: www.voltairenet.org/article121628.html, último acesso: 24.03.2006). 
MATTELART, Armand (2005). "Novas frentes de luta na comunicação" entrevista realizada por Dica Sitoni e James Gorgen in: The independent family of publication from inter press service. 01.2005 (in: www.ipsterraviva.net/TV/WSF2005/viewstory.asp?idnews=135, último acesso: 23.03.2006).

ORTIZ LEIVA, Germán (2001). “¿Por qué un Observatório de Medios en Colombia?”, Sala de Prensa. Peru: n. 37, ano III, vol. 2 (in: www.saladeprensa.org/art293.htm, último acesso: 24.03.2006).

PNUD (2004). "Experiencias comparativas - PNUD Honduras. Observatorios de Desarrollo Humano" in: Programa de las Naciones Unidas para el Desarrollo (PNUD). Panamá (in: www.undp.org/surfpanama/docs/observatórios dh.doc, último acceso: 22.04.2006).

POBRETE MAUREIRA, Paula (2004). Ponencia presentada en la sección "Observatorios de Políticas Culturales: experiencias locales y regionales" in: II Encuentro Internacional sobre Diversidad Cultural. Buenos Aires (in: www.buenosaires.gov.ar/areas/cultura/observatório/index.php?menu id=69 33, último acesso: 28.03.2006).

RAMONET, Ignacio (2003). "Fiscalización ciudadana a los medios de comunicación: el quinto poder" in Le Monde Diplomatique. Paris (in: http://www.geocities.com/lospobresdelatierra2/altermedia/ramonet151003. html , último acesso: 01.06.2006).

REY, Germán (2003). "Ver desde la Ciudadanía" in: Observatorios y Veedurías de Medios de Comunicación en América Latina. Colômbia (in: www.veeduria.org.pe/articulos/rey.htm, último acesso:14.03.2006). 